\title{
The gene mutational discrepancies between primary and paired metastatic colorectal carcinoma detected by next-generation sequencing
}

\author{
Shuang-Mei Zou ${ }^{1} \mathbb{D} \cdot$ Wei-Hua $\mathrm{Li}^{1} \cdot$ Wen-Miao Wang ${ }^{1} \cdot$ Wen-Bin $\mathrm{Li}^{1} \cdot$ Su-Sheng Shi ${ }^{1} \cdot$ Jian-Ming Ying ${ }^{1} \cdot$ Ning Lyu $^{1}$
}

Received: 15 May 2018 / Accepted: 21 August 2018 / Published online: 31 August 2018

(c) The Author(s) 2018

\begin{abstract}
Purpose To better understand the gene mutational status and heterogeneity between primary and metastatic CRC (mCRC) using a sensitive sequencing method.

Methods The mutational status of EGFR, KRAS, NRAS, PIK3CA, ERBB2, BRAF, KIT, and PDGFRA was analyzed in 65 patients, with 147 samples of primary and paired live or lung metastatic CRC, using next-generation sequencing (NGS), quantitative RT-PCR (qPCR), and Sanger sequencing.

Results Fifteen cases $(15 / 22,68.2 \%)$ of lung mCRC and thirteen cases $(13 / 20,65 \%)$ of liver mCRC harboured the same mutation profiles of KRAS, NRAS, or BRAF in the primary lesions. To all detected genes, 11 cases $(11 / 22,50 \%)$ of lung mCRC and 11 cases $(11 / 20,55 \%)$ of liver mCRC showed different mutational genes in the primary tumours. KRAS and BRAF mutations were more frequent in lung metastatic lesions ( $p=0.004$ and 0.003 , respectively). The gene mutations in KRAS, $N R A S, B R A F$, and PIK3CA in the lung metastatic sites were more frequent than those in the liver metastatic sites (86.7 vs. $44 \%$, respectively, $p=0.000$ ). Some new mutations were not covered in the qPCR ranges but were detected by NGS.

Conclusion The study demonstrated that the discordance of gene mutational status between paired primary and metastatic tumours is rather high when detected by NGS. Evaluating the mutational status of both the primary and metastatic tumours should be considered in clinical mutation testing.
\end{abstract}

Keywords Metastatic CRC $\cdot$ Gene mutation $\cdot$ Next-generation sequencing $\cdot R A S \cdot B R A F \cdot P I K 3 C A$

\section{Introduction}

Colorectal cancer (CRC) is one of the most common malignancies, and it is the fifth leading cause of cancer-related deaths in China (Chen et al. 2016). Invasion and metastasis account for the high mortality rate of CRC. Targeted

Ning Lyu and Jian-Ming Ying have equally contributed to this paper.

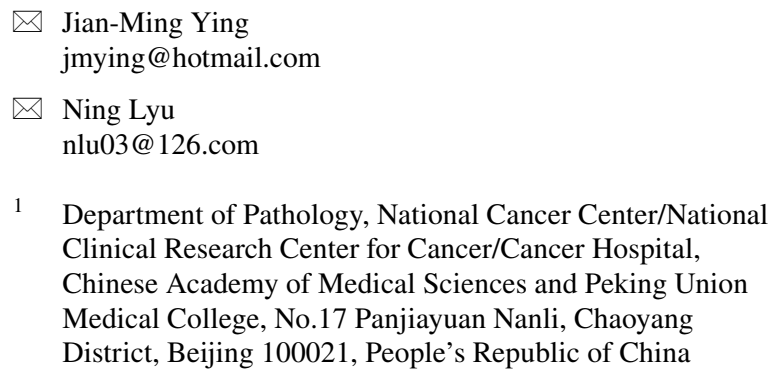

1 Department of Pathology, National Cancer Center/National Clinical Research Center for Cancer/Cancer Hospital, Chinese Academy of Medical Sciences and Peking Union Medical College, No.17 Panjiayuan Nanli, Chaoyang District, Beijing 100021, People's Republic of China

therapies have transformed the current strategies in tumour treatment. Patients with metastatic CRC (mCRC) have greatly benefited from antibody-mediated blockade of the epidermal growth factor receptor (EGFR), with antibodies such as cetuximab and panitumumab (Dietel et al. 2015).

The EGFR signalling pathway plays a pivotal role in the proliferation and survival of CRC (Efferth 2012). The targeted drug that blocks EGFR is a therapeutic option in the treatment of mCRC. However, mutations in the genes downstream of the EGFR signalling pathway result in a constitutive activation of the EGFR and thus might abolish the effects of EGFR antibodies (Sinicrope et al. 2016). KRAS and NRAS are some of these well-known genes. BRAF and PIK3CA mutations may also be negative predictive biomarkers for anti-EGFR therapies (Nakayama et al. 2017). Moreover, other cancer-related genes, such as KIT and PDGFRA, may also act as important predictive and prognostic markers in CRC ( $\mathrm{Li}$ et al. 2016). Therefore, it is essential to accurately detect the mutational status of CRC. The selection 
of suitable tissue samples is critical for accurate mutation detection but is challenging for pathologists (Van Cutsem et al. 2016). Some studies reported that the concordance in KRAS mutational status between the primary and the metastatic tumours is high, and tissue from either the primary tumour or metastasis may be used for testing mutations according to the latest NCCN guidelines for the treatment of mCRC (Han et al. 2012). However, some studies find that spatial and temporal tumour heterogeneity, which exists between the primary and the metastatic tumours, is significant and thus accounts for targeted therapy failure (Goswami et al. 2015).

Next-generation sequencing has been widely used in mutation detection in recent years, as it provides high analytic sensitivity and a broad reportable range (Haley et al. 2015). NGS has become a robust tool for molecular diagnosis of CRC (Kothari et al. 2014; Malapelle et al. 2015). Moreover, NGS can provide a quantitative measurement of mutant allele frequencies and predict tumour heterogeneity. In this study, we compared the mutational status between primary CRC and paired liver or lung metastasis by NGS, qPCR, and Sanger sequencing assays. We hope that this study may help in better understanding the mutational status and heterogeneity in $\mathrm{mCRC}$ and selecting suitable samples and technology for the accurate mutation detection of CRC by pathologists.

\section{Materials and methods}

\section{Patient selection}

This study included patients from a consecutive pathology database with surgically resected liver or lung mCRC in the Department of Pathology, Cancer Hospital, Chinese Academy of Medical Sciences, and Peking Union Medical College from 2007 to 2015, whose primary CRC was also resected at this hospital. Both the primary and metastatic resected specimens could be obtained for testing. At the time of surgical resection of $\mathrm{mCRC}$, the patients had only lung or liver metastasis, but other metastatic sites, such as peritoneal, brain, ovary, etc., were not excluded. Patients who underwent neoadjuvant therapy before resection of primary tumours were not chosen for the study. All patients were not treated with cetuximab or other targeted agents before or after surgical resections of the primary or metastatic CRC.

\section{Specimen selection}

For each patient, every lesion of both primary and metastasis CRC was taken out, and the H\&E slides were evaluated by two pathologists (SMZ and JMY). One of the representative paraffin blocks from each lesion was chosen for testing. A tumour content of more than $50 \%$ was usable for DNA extraction.

\section{Genomic DNA extraction and quantitation}

The genomic DNA from no less than five consecutive, 5 $\mu \mathrm{m}$-thick slides of FFPE samples was extracted using the QIAamp DNA FFPE Tissue Kit (Qiagen, Hilden, Germany) per the manufacturer's instructions. The DNA concentration was determined by the genomic DNA quantitative detection kit (Beijing ACCB Biotech Ltd., Beijing, China) on a CFX96 RT-PCR instrument (Bio-Rad, California, USA), and it was normalized to approximately $20-50 \mathrm{ng} / \mu \mathrm{l}$. The DNA samples were stored at $-20^{\circ} \mathrm{C}$ before utilization.

\section{Mutation analysis by next-generation sequencing (NGS)}

The NextDaySeq colon panel on the Ion TorrentTM System (Manufactured by Beijing ACCB Biotech, Beijing, China) was used to construct libraries according to the manufacturer's instructions. Briefly, genomic regions of EGFR exons 18, 19, 20, and 21; KRAS exons 2 and 3; NRAS exons 2 and 3; PIK3CA exons 9 and 20; ERBB2 exon 20; BRAF exons 11 and 15; KIT exons 9, 11, 13, 14, and 17; and PDGFRA exons 12,14 , and 18 were amplified with pooled primer pairs, followed by ligations of the adaptors and barcodes. The libraries were purified and quantified using a Qubit dsDNA HS Assay Kit on a Qubit 2.0 fluorometer (Thermo Fisher Scientific, Waltham, MA, USA); they were then diluted to a concentration of $3 \mathrm{ng} / \mathrm{ml}$ and pooled. The library pool was sequenced using the Ion Torrent PGM system. Briefly, the library pool was clonally amplified in an emulsion PCR reaction using Ion Sphere Particles on the OneTouch 2 instrument (Thermo Fisher Scientific). Template-positive ion sphere particles were enriched on the Ion OneTouch ES (Thermo Fisher Scientific). After enrichment, the sequencing primers and polymerase were added from the Ion PGM ${ }^{\mathrm{TM}}$ Sequencing Supplies 200 v2 Kit (Thermo Fisher Scientific). The libraries were loaded to generate sequencing data on the Ion 318 chips (Thermo Fisher Scientific) and sequenced on an Ion Torrent PGM (Thermo Fisher Scientific). A proprietary bioinformatics pipeline, the DanPA bioinformatics pipeline, was employed for variant calling and annotation. The pipeline was specifically designed for the NextDaySeq panels. The cutoff of mutation frequency for mutation calling was $1 \%$, and that of mutation reads was 5 . 


\section{Mutation analysis by quantitative RT-PCR (qPCR)}

Mutation profiles of $E G F R, K R A S, N R A S, B R A F$, and $P I K 3 C A$ were detected using the corresponding Human Gene Mutations Detection Kit, Human KRAS Gene Mutations Detection Kit, Human NRAS Gene Mutations Detection Kit, Human BRAF Gene Mutations Detection Kit, and Human PIK3CA Gene Mutations Detection Kit (Real-time Fluorescent PCR, Beijing ACCB Biotech Ltd., Beijing, China), respectively. The tests cover 72 hotspot mutations including 45 in exons 18, 19, 20, and 21 of EGFR; 12 in exons 2 and 3 of KRAS; 9 in exons 2 and 3 of NRAS; 5 in exons 9 and 20 of PIK3CA; BRAF V600E. The quantitative PCR was performed on an Mx3000P PCR instrument (Agilent, CA, USA) with the following settings: $95^{\circ} \mathrm{C}$ for $10 \mathrm{~min} ; 40$ cycles of $95^{\circ} \mathrm{C}$ for $15 \mathrm{~s}$ and $60{ }^{\circ} \mathrm{C}$ for $1 \mathrm{~min}$. The results were interpreted as per the manufacturer's instructions.

\section{Mutation analysis by Sanger sequencing}

The same genomic regions of eight genes covered in the NextDaySeq colon panel were amplified and sequenced bidirectionally with the ABI Prism Big Dye Terminator v 3.1 Cycle Sequencing Kit on an ABI 3130XL Genetic Analyzer (Thermo Fisher Scientific) according to the manufacturer's instructions.

\section{Definition of the gene mutation type}

The wild type was defined as having no gene mutations detected in the gene panel by any of the gene sequencing methods. The mutant type was defined as having any mutation detected in the gene panel by any of the gene sequencing methods. A single mutation was defined as having only one gene mutation in the gene panel detected by any of the gene sequencing methods. The combined mutation was defined as having more than one gene mutation in the gene panel detected by any of the gene sequencing methods.

\section{Statistics}

Statistical analyses were performed with SPSS 25.0 software (SPSS, Chicago, IL). To evaluate the statistical significance of the differences observed between the groups, a Chi-square test was applied. To be specific, the Pearson's chi-square test, the Fisher's exact test, and continuity correction were used in different situations. All $P$ values represent two-sided statistical tests and only those with less than 0.05 were considered significant.

\section{Results}

\section{Basic characteristics of patients and primary CRC}

Seventy-five patients with the primary and paired metastatic CRCs were chosen for the study. In ten of the cases, either the primary or the metastatic specimen failed the gene mutation test because of poor DNA quality. Finally, a total of 65 CRC patients, including 29 patients with lung metastasis and 36 patients with liver metastasis, were included in this study. They were divided into two groups according to the different metastasis locations. There were 42 males and 23 females; the median age was 58 years (30-78 years). No statistical difference was found between the two groups based on sex and age $(p=0.891)$. Some of the patients had more than one primary and metastatic CRC lesion. As a whole, 147 samples of primary CRC lesions and the paired metastases samples were analyzed.

There were 13 cases of primary CRC tumours that were located in the right half colon (caecum to transverse colon), 15 were located in the left half colon (descended to rectosigmoid colon), and 37 were located in the rectum. Fiftysix cases were well differentiated (G1/G2) and nine cases were poorly differentiated (G3/G4) according to the 2010 WHO classification of gastrointestinal tumours. Pathologic TNM classification was done according to the AJCC 7 th. T3 took the majority between the two groups (48/65, $74 \%)$, followed by T4a $(9 / 65,14 \%)$. More than two-thirds of patients suffered from lymph node metastasis. Three cases had additional peritoneal metastasis besides liver metastasis. There was no significant difference between the two groups on the primary tumour characteristics, including location, differentiation, and $\mathrm{T}$ and $\mathrm{N}$ classifications. Twenty-nine and thirty-six cases had synchronous or metachronous distant metastasis, respectively. Synchronous metastasis was more common in the liver than it was in the lung metastasis group ( $p=0.000)$. Therefore, the median time from primary tumour resections to metastasis resections was much longer in the lung metastasis group (23, 1-61 months) than that in the liver metastasis group (0, 0-35 months). The patient and primary tumour characteristics are summarized in Table 1.

\section{Gene mutational status detected by qPCR, NGS, and Sanger sequencing}

All the 147 samples were sequenced by both NGS and qPCR. Ninety-five samples were mutant type. The KRAS, NRAS, BRAF, PIK3CA, EGFR, KIT, and PDGFRA mutation detected by either NGS or qPCR was 54 (36.73\%), 11 (7.48\%), 6 (4.08\%), 18 (12.24\%), 3 (2.04\%), 2 (1.36\%), and $1(0.68 \%)$, respectively. NGS detected more mutations than 
Table 1 Baseline characteristics of patients and their primary CRC $(n=65)$
Cases with only lung Cases with only liver $P$ value metastasis $(N=29) \quad$ metastasis $(N=36)$

\begin{tabular}{|c|c|c|c|}
\hline \multicolumn{4}{|l|}{ Sex } \\
\hline Male & 19 & 23 & \multirow[t]{3}{*}{0.891} \\
\hline Female & 10 & 13 & \\
\hline Median age (range) & $59(30-78)$ & $58(36-75)$ & \\
\hline \multicolumn{4}{|l|}{ Location of primary tumours } \\
\hline Left half colon & 7 & 8 & \multirow[t]{3}{*}{0.528} \\
\hline Right half colon & 4 & 9 & \\
\hline Rectum & 18 & 19 & \\
\hline \multicolumn{4}{|l|}{ Differentiation } \\
\hline $\mathrm{G} 1 / \mathrm{G} 2$ & 27 & 29 & \multirow[t]{2}{*}{0.122} \\
\hline G3/G4 & 2 & 7 & \\
\hline \multicolumn{4}{|l|}{ T stage } \\
\hline 2 & 4 & 2 & \multirow[t]{4}{*}{0.168} \\
\hline 3 & 19 & 29 & \\
\hline $4 \mathrm{a}$ & 6 & 3 & \\
\hline $4 \mathrm{~b}$ & 0 & 2 & \\
\hline \multicolumn{4}{|l|}{$\mathrm{N}$ stage } \\
\hline 0 & 9 & 6 & \multirow[t]{5}{*}{0.566} \\
\hline $1 \mathrm{a}$ & 6 & 7 & \\
\hline $1 b$ & 6 & 12 & \\
\hline $2 \mathrm{a}$ & 5 & 5 & \\
\hline $2 b$ & 3 & 6 & \\
\hline \multicolumn{4}{|l|}{ M stage } \\
\hline M0 & 26 & 15 & \multirow[t]{3}{*}{0.000} \\
\hline M1a & 3 & 18 & \\
\hline M1b & 0 & 3 & \\
\hline \multicolumn{4}{|l|}{ TNM stages } \\
\hline I & 3 & 0 & \multirow[t]{4}{*}{0.000} \\
\hline II & 4 & 4 & \\
\hline III & 19 & 11 & \\
\hline IV & 3 & 21 & \\
\hline \multicolumn{4}{|l|}{ History of treatments } \\
\hline None & 23 & 19 & \multirow[t]{3}{*}{0.027} \\
\hline Neoadjuvant therapy & 1 & 0 & \\
\hline Adjuvant therapy & 5 & 17 & \\
\hline $\begin{array}{l}\text { Median time of duration of time between the } \\
\text { resection of primary lesions and metastases } \\
\text { (range } \mathrm{m} \text { ) }\end{array}$ & $23(1-61)$ & $0(0-35)$ & \\
\hline Metastatic type & & & 0.000 \\
\hline Synchronous & 8 & 21 & \\
\hline Metachronous & 21 & 15 & \\
\hline
\end{tabular}

qPCR did (83 vs 76, respectively), especially for PIK3CA. NGS found 18 PIK3CA mutations, while qPCR only detected nine mutations. A total of 14 mutations were detected only by NGS, which are 1 KRAS L52P, 3 NRAS A91V, 1 BRAF G469A, 2PIK3CA E545A, 2 PIK3CA Q546K, 1 EGFR G735C, 1 EGFR G796S, 1 KIT W557*, 1 KIT P573L, and 1 PDGFRA M648fs (the details are shown in Table 2).
Sanger sequencing was performed in the first 16 tested cases, with 32 samples. Only 20 samples, including 9 wild type and 11 mutant type, showed the same results with NGS or qPCR method. Twelve samples were not consistent with NGS or qPCR results, which were nine samples mutant type in NGS or qPCR, but were wild type in Sanger sequencing. The other three cases were no results by Sanger sequencing. In addition, no mutations that were found by Sanger sequencing 
Table 2 Gene mutational status detected by qPCR and NGS

\begin{tabular}{|c|c|c|c|c|c|c|c|}
\hline Gene & Total $(N=147)(\%)$ & $\begin{array}{l}\text { Single mutation } \\
(\%)\end{array}$ & $\begin{array}{l}\text { Combined } \\
\text { mutation } \\
(\%)\end{array}$ & $\begin{array}{l}\text { Mutation } \\
\text { by qPCR } \\
(\%)\end{array}$ & $\begin{array}{l}\text { Mutation by NGS } \\
(\%)\end{array}$ & $\begin{array}{l}\text { qPCR and NGS } \\
\text { concordance }(\%)\end{array}$ & $\begin{array}{l}\text { New locus detected } \\
\text { by NGS }\end{array}$ \\
\hline$K R A S$ & $54(36.73)$ & $43(29.25)$ & $11(7.48)$ & $53(36.05)$ & 47 (31.97) & $46(85.19, n=54)$ & 1 KRAS L52P \\
\hline$N R A S$ & $11(7.48)$ & $7(4.76)$ & $3(2.04)$ & $8(5.44)$ & $9(6.12)$ & $6(54.54, n=11)$ & 3 NRAS A91V \\
\hline$B R A F$ & $6(4.08)$ & $2(1.36)$ & $4(2.72)$ & $5(3.40)$ & $6(4.08)$ & $4(66.67, n=6)$ & $1 B R A F$ G469A \\
\hline PIK3CA & $18(12.24)$ & $4(2.72)$ & $13(8.84)$ & $9(6.12)$ & $18(12.24)$ & $9(50.00, n=18)$ & $\begin{array}{l}2 \text { 2PIK3CA E545A, } \\
2 \text { PIK3CA Q546K }\end{array}$ \\
\hline$E G F R$ & $3(2.04)$ & $2(1.36)$ & $1(0.68)$ & $1(0.68)$ & $3(0.20)$ & $2(66.67, n=3)$ & $\begin{array}{c}1 \text { EGFR G735C, } 1 \\
E G F R \text { G796S }\end{array}$ \\
\hline KIT & $2(1.36)$ & $2(1.36)$ & $0(0)$ & $0(0)$ & $2(1.36)$ & $0(0, n=2)$ & $\begin{array}{l}1 \text { KIT W557*, } 1 \text { KIT } \\
\text { P573L }\end{array}$ \\
\hline PDGFRA & $1(0.68)$ & $0(0)$ & $1(0.68)$ & $0(0)$ & $1(0.68)$ & $0(0, n=1)$ & 1 PDGFRA M648fs \\
\hline Total & $95(64.63)$ & $60(40.82)$ & $33(22.45)$ & $76(80.00)$ & 83 (87.37) & $67(70.53)$ & 14 \\
\hline
\end{tabular}

were not detected by NGS or qPCR. The results showed that the low sensitivity of Sanger sequencing compared with the other two methods.

\section{Gene mutations in the primary and the metastatic CRC}

Twenty-nine cases, with fifty-nine paired primary and lung metastatic CRC tissues, were analyzed. One case (No. 20) had two lung metastatic loci. Both the primary and the paired lung metastatic CRC were wild type in 7 patients $(7 / 29,24.1 \%)$. Gene mutations were found in the left 22 cases, $18(18 / 29,62.1 \%)$ in the primary sites, and $20(20 / 30$, $66.7 \%)$ in the metastatic sites. A total of 46 gene mutations were found, $20(20 / 46,43.5 \%)$ in the primary sites, and 26 $(26 / 46,56.5 \%)$ in the metastatic sites. In the primary sites, the gene mutations included 14 in KRAS, 2 in NRAS, 1 in PIK3CA, 2 in BRAF-V600E, 1 in KIT W557*, 1 in PDGFRA M648fs. The gene mutations in the metastatic sites were 17 in KRAS, 1 in NRAS, 3 in PIK3CA, 4 in BRAF, and 1 in EGFR (the details are shown in Table 3). The KRAS mutations were most frequent both in the primary and the metastatic CRCs (13/20, 65\% and 17/26, 65.4\%, respectively). Some mutations were detected by NGS and not included in the qPCR genomic regions, which were KIT W557*, PDGFRA M648fs, KRAS L52P, and BRAF G469A.

Thirty-six cases, with eighty-eight paired primary and liver metastatic CRC, were analyzed. Two cases had two primary sites; and three, two, and one cases had two, three, and eight metastatic sites, respectively. Both the primary and paired liver metastatic CRC were wild type in 16 patients $(16 / 36,44.4 \%)$. Gene mutations were found in 20 cases, 18 $(18 / 20,90 \%)$ from the primary site, and $17(17 / 20,85 \%)$ from the metastatic sites. A total of 49 gene mutations were found: $27(27 / 49,55.1 \%)$ from the primary sites and 22 $(22 / 49,44.9 \%)$ from the metastatic sites. There were more gene mutations in the primary sites than those in the metastatic sites. In the primary sites, gene mutations included 13 in $K R A S, 5$ in NRAS, 8 in PIK3CA, and 1 in EGFR. The gene mutations in the metastatic sites were 11 in $K R A S$, 3 in NRAS, 6 in PIK3CA, 1 in KIT, and 1 in EGFR. No $B R A F$ mutation was found in either the primary or the liver metastatic CRC (the details are shown in Table 3). Some mutations were detected by NGS and were not included in the qPCR genomic regions, which were KIT P573L, EGFR G735C, and EGFR G796S.

When comparing the mutational gene status between the primary site of CRC with lung and liver metastasis (the details are shown in Table 3 ), we found that there was no significant difference in KRAS, NRAS, BRAF, and PIK3CA. Regarding the metastatic site, gene mutations in the lung metastatic sites were significantly much more prevalent than those in the liver metastatic sites $(p=0.000)$, with a total 26 gene mutations $(26 / 30,86.7 \%)$ and 22 gene mutations $(22 / 50,44 \%)$, respectively. We also found 17 and $11 K R A S$ gene mutation in the lung metastasis and liver metastasis, respectively ( 56.7 vs. $22 \%, p=0.002)$.

\section{The mutational consistency between paired primary and lung metastatic CRC}

Fifteen cases $(15 / 22,68.2 \%)$ harboured the same mutation profiles between the primary and the lung metastatic lesions in $K R A S, N R A S$, and $B R A F$, which were $4 K R A S \mathrm{G} 12 \mathrm{D}$, 6 KRAS G13D, 1 KRAS G12R, 1 KRAS G12A, 1 NRAS G12D, and 2 BRAF V600E. All were CRCs with metachronous metastasis. Eleven cases $(11 / 22,50 \%)$ harboured the exactly the same mutation between the primary and the lung metastatic lesions. The other 11 cases $(11 / 22,50 \%)$ showed somewhat different mutational genes (the details are shown in Table 4). Five of these cases showed gene mutation discrepancies beside $K R A S, N R A S$, and $B R A F$, which were 
Table 3 Gene mutations in the primary and the metastatic CRC

\begin{tabular}{|c|c|c|c|c|c|c|}
\hline Mutant genes & $\begin{array}{l}\text { Primary site of CRC } \\
\text { with lung metastasis } \\
(n=29)\end{array}$ & $\begin{array}{l}\text { Primary site of CRC } \\
\text { with liver metastasis } \\
(n=38)\end{array}$ & $P$ value & $\begin{array}{l}\text { Metastatic site of CRC } \\
\text { with lung metastasis } \\
(n=30)\end{array}$ & $\begin{array}{l}\text { Metastatic site of CRC } \\
\text { with liver metastasis } \\
(n=50)\end{array}$ & $P$ value \\
\hline$K R A S$ & 13 & 13 & 0.377 & 17 & 11 & 0.002 \\
\hline$K R A S \mathrm{G} 12 \mathrm{D}$ & 5 & 7 & 0.901 & 5 & 6 & 0.557 \\
\hline$K R A S$ G13D & 6 & 2 & 0.121 & 6 & 2 & 0.054 \\
\hline$K R A S \mathrm{G} 12 \mathrm{~V}$ & 0 & 3 & & 2 & 1 & \\
\hline$K R A S$ G12R & 1 & 0 & & 1 & 0 & \\
\hline$K R A S$ G12A & 1 & 0 & & 1 & 0 & \\
\hline$K R A S \mathrm{G} 12 \mathrm{C}$ & 0 & 0 & & 1 & 0 & \\
\hline KRAS Q61H & 0 & 1 & & 0 & 2 & \\
\hline$K R A S$ L52P & 0 & 0 & & 1 & 0 & \\
\hline$N R A S$ & 2 & 5 & 0.406 & 1 & 3 & 0.596 \\
\hline NRAS Q61K & 1 & 0 & & 0 & 0 & \\
\hline$N R A S$ G12D & 1 & 2 & & 1 & 2 & \\
\hline$N R A S$ Q61R & 0 & 1 & & 0 & 0 & \\
\hline NRAS A91V & 0 & 2 & & 0 & 1 & \\
\hline$B R A F$ & 2 & 0 & 0.184 & 4 & 0 & 0.034 \\
\hline$B R A F \mathrm{~V} 600 \mathrm{E}$ & 2 & 0 & & 3 & 0 & \\
\hline$B R A F \mathrm{G} 469 \mathrm{~A}$ & 0 & 0 & & 1 & 0 & \\
\hline$P I K 3 C A$ & 1 & 8 & 0.083 & 3 & 6 & 1.000 \\
\hline$P I K 3 C A$ E545A & 1 & 1 & & 0 & 0 & \\
\hline$P I K 3 C A$ E $545 \mathrm{~K}$ & 0 & 3 & & 0 & 1 & \\
\hline PIK3CA Q546K & 0 & 1 & & 0 & 1 & \\
\hline$P I K 3 C A \mathrm{E} 542 \mathrm{~K}$ & 0 & 1 & & 2 & 1 & \\
\hline PIK3CA H1047R & 0 & 2 & & 1 & 3 & \\
\hline KIT W557* & 1 & 0 & & 0 & 0 & \\
\hline KIT P573L & 0 & 0 & & 0 & 1 & \\
\hline PDGFRA M648fs & 1 & 0 & & 0 & 0 & \\
\hline$E G F R$ G735C & 0 & 1 & & 0 & 0 & \\
\hline$E G F R$ L858R & 0 & 0 & & 1 & 0 & \\
\hline EGFR G796S & 0 & 0 & & 0 & 1 & \\
\hline Total & 20 & 27 & 0.853 & 26 & 22 & 0.000 \\
\hline
\end{tabular}

EGFR L858R, PIK3CA H1047R, PIK3CA E542K, PDG$F R A$ M648fs, and KIT W557*. In the other six cases, the gene mutation profiles were different in KRAS, NRAS, or $B R A F$, and five of them were metachronous metastasis. Only five cases underwent adjuvant chemotherapy or radiochemotherapy after primary tumour was resected, the gene mutation inconsistent cases were not statistical different between adjuvant and non-adjuvant therapy groups.

\section{The mutational consistency between paired primary and liver metastatic CRC}

Thirteen cases $(13 / 20,65 \%)$ harboured the same mutation profiles between the primary and the liver metastatic lesions in KRAS, NRAS, and BRAF, which were KRAS
G12D, 1 KRAS G13D, 1 KRAS G12V, 1 KRAS Q61H, 1 NRAS G12D, 1 NRAS A91V, 1 PIK3CA E542K, 1 KRAS G13D and PIK3CA Q546K, and 1 PIK3CA H1047R and $N R A S$ G12D. Nine cases $(9 / 20,45 \%)$ harboured the exactly the same mutation between the primary and the liver metastatic lesions. The other 11 cases $(11 / 20,55 \%)$ showed somewhat different mutational genes (the details are shown in Table 5). Six of these cases showed gene mutation discrepancies beside $K R A S, N R A S$, and $B R A F$, which were PIK3CA E545K, PIK3CA H1047R, EGFR G796S, and KIT P573L. In the other five cases, the gene mutation profiles were different in KRAS, NRAS, or BRAF. Most of these mutation inconsistent cases were with synchronous metastasis $(9 / 11,81.8 \%)$, there were 17 cases underwent adjuvant therapy. The mutation inconsistent cases were 
Table 4 Mutational cases in paired primary and lung metastatic CRC $(n=22)$

\begin{tabular}{|c|c|c|c|c|c|c|}
\hline \multirow[t]{2}{*}{ Mutational consistency } & \multirow[t]{2}{*}{ No. } & \multirow[t]{2}{*}{ Case no. } & \multicolumn{2}{|l|}{ Mutational type } & \multirow{2}{*}{$\begin{array}{l}\text { Synchronous }(\mathrm{S}) / \\
\text { metachronous }(\mathrm{M}) \\
\text { metastasis }\end{array}$} & \multirow{2}{*}{$\begin{array}{l}\text { Adjuvant(A)/ } \\
\text { non-adjuvant }(\mathrm{N}) \\
\text { therapy }\end{array}$} \\
\hline & & & Primary site & Metastatic site & & \\
\hline \multirow{11}{*}{$\begin{array}{l}\text { Mutation consistent cases } \\
\qquad(n=11)\end{array}$} & 1 & Lung01 & $K R A S$ G13D & $K R A S$ G13D & M & $\mathrm{N}$ \\
\hline & 2 & Lung04 & $K R A S$ G12D & $K R A S$ G12D & M & $\mathrm{N}$ \\
\hline & 3 & Lung07 & $K R A S \mathrm{G} 12 \mathrm{D}$ & $K R A S \mathrm{G} 12 \mathrm{D}$ & M & A \\
\hline & 4 & Lung09 & $K R A S \mathrm{G} 13 \mathrm{D}$ & $K R A S \mathrm{G} 13 \mathrm{D}$ & M & $\mathrm{N}$ \\
\hline & 5 & Lung12 & $K R A S$ G12D & $K R A S$ G12D & M & A \\
\hline & 6 & Lung13 & $K R A S$ G13D & $K R A S$ G13D & M & $\mathrm{N}$ \\
\hline & 7 & Lung21 & $K R A S$ G12R & $K R A S$ G12R & M & $\mathrm{N}$ \\
\hline & 8 & Lung23 & $K R A S \mathrm{G} 12 \mathrm{~A}$ & $K R A S \mathrm{G} 12 \mathrm{~A}$ & M & $\mathrm{N}$ \\
\hline & 9 & Lung24 & $K R A S \mathrm{G} 13 \mathrm{D}$ & $K R A S \mathrm{G} 13 \mathrm{D}$ & M & $\mathrm{N}$ \\
\hline & 10 & Lung25 & $K R A S$ G12D & $K R A S$ G12D & M & $\mathrm{N}$ \\
\hline & 11 & Lung26 & $N R A S$ G12D & NRAS G12D & M & $\mathrm{N}$ \\
\hline \multirow{5}{*}{$\begin{array}{l}\text { Mutation inconsistent cases } \\
\text { beside } K R A S, N R A S \text { or } \\
B R A F(n=5)\end{array}$} & 12 & Lung06 & $K R A S$ G13D & $K R A S$ G13D, EGFR L858R & M & A \\
\hline & 13 & Lung10 & $K R A S$ G13D & $\begin{array}{l}\text { KRAS G13D, PIK3CA } \\
\text { H1047R }\end{array}$ & M & $\mathrm{N}$ \\
\hline & 14 & Lung20 & $B R A F \mathrm{~V} 600 \mathrm{E}$ & $\begin{array}{l}\mathrm{M}^{\mathrm{a}}: B R A F \mathrm{~V} 600 \mathrm{E}, P I K 3 C A \\
\text { E542K } \\
\mathrm{M}^{\mathrm{b}}: B R A F \mathrm{~V} 600 \mathrm{E}, P I K 3 C A \\
\text { E542K }\end{array}$ & M & $\mathrm{N}$ \\
\hline & 15 & Lung15 & $\begin{array}{l}\text { BRAF V600E } \\
P D G F R A \text { M648fs }\end{array}$ & $B R A F$ V600E & M & $\mathrm{N}$ \\
\hline & 16 & Lung03 & KIT W557* & Wild type & M & $\mathrm{N}$ \\
\hline \multirow{6}{*}{$\begin{array}{l}\text { Mutation inconsistent cases } \\
\text { in KRAS, NRAS and BRAF } \\
(n=6)\end{array}$} & 17 & Lung18 & Wild type & KRAS G12D & M & $\mathrm{N}$ \\
\hline & 18 & Lung19 & Wild type & $K R A S \mathrm{G} 12 \mathrm{D}$ & M & $\mathrm{N}$ \\
\hline & 19 & Lung27 & Wild type & $K R A S$ G12C & $\mathrm{S}$ & $\mathrm{N}$ \\
\hline & 20 & Lung28 & Wild type & $K R A S$ L52P, BRAF G469A & M & $\mathrm{N}$ \\
\hline & 21 & Lung17 & $\begin{array}{l}\text { KRAS G12D } \\
P I K 3 C A \text { E545A }\end{array}$ & Wild type & M & A \\
\hline & 22 & Lung14 & NRAS Q61K & $K R A S$ G12D & $\mathrm{M}$ & $\mathrm{N}$ \\
\hline
\end{tabular}

${ }^{\mathrm{a}}$ Lung metastatic site 1

${ }^{\mathrm{b}}$ Lung metastatic site 2

more in non-adjuvant therapy group than in adjuvant therapy group $(9 / 19$ vs $2 / 17, P=0.021)$.

\section{Gene mutation discrepancies among the separate primary or metastatic site(s) in one case}

For those cases with more than one primary or metastatic site, each site was sequenced separately. We did observed that gene mutational status discrepancies were exist in CRC with liver metastasis. The details were summarized in Table 6. Case Liver 04 was a rectal cancer patient who suffered multiple simultaneous liver metastases in the sixth and seventh hepatic segment. The patient had a KIT P573L mutation only in the seventh hepatic segment lesion, while both the primary and the sixth hepatic segment metastatic lesions were wild type. Case Liver 28 was a patient with two primary lesions in the rectum and one simultaneous liver metastatic lesion in the seventh hepatic segment. The NRAS
A91V mutation could be detected in all three lesions in this case, while the NRAS Q61R mutation was only detected in one of the primary lesions.

\section{Discussion}

KRAS and NRAS mutations are critical negative predictors of anti-EGFR therapy. In addition to KRAS and NRAS mutations, $B R A F$ and PIK3CA mutations may also be potential biomarkers of resistance to anti-EGFR targeted treatments (Hsu et al. 2016; Karthaus et al. 2016). Some studies find that high concordance can be observed between the primary and metastatic tumours, suggesting that the detection of one lesion is sufficient to predict the response to EGFR-targeted therapy (Artale et al. 2008; Knijn et al. 2011; Santini et al. 2008). Therefore, the latest NCCN guideline strongly recommends genotyping of tumour tissue (either primary tumour 
Table 5 Mutational cases in paired primary and liver metastatic CRC $(n=20)$

\begin{tabular}{|c|c|c|c|c|c|c|}
\hline \multirow[t]{2}{*}{ Mutational consistency } & \multirow[t]{2}{*}{ No. } & \multirow[t]{2}{*}{ Case no. } & \multicolumn{2}{|l|}{ Mutation types } & \multirow{2}{*}{$\begin{array}{l}\text { Synchronous } \\
(\mathrm{S}) \text { or } \\
\text { metachronous (M) } \\
\text { metastasis }\end{array}$} & \multirow{2}{*}{$\begin{array}{l}\text { Adjuvant(A) } \\
\text { or } \\
\text { non-adju- } \\
\text { vant }(\mathrm{N}) \\
\text { therapy }\end{array}$} \\
\hline & & & Primary site & Metastatic site & & \\
\hline \multirow[t]{9}{*}{ Mutation consistent cases $(n=9)$} & 1 & Liver 02 & $\begin{array}{l}\text { NRAS G12D } \\
\text { PIK3CA H1047R }\end{array}$ & $\begin{array}{l}\text { NRAS G12D } \\
P I K 3 C A \text { H1047R }\end{array}$ & $\mathrm{S}$ & A \\
\hline & 2 & Liver 03 & KRAS G12D & $K R A S$ G12D & $\mathrm{S}$ & $\mathrm{N}$ \\
\hline & 3 & Liver 10 & NRAS G12D & NRAS G12D & M & A \\
\hline & 4 & Liver 12 & $K R A S \mathrm{Q} 61 \mathrm{H}$ & $K R A S \mathrm{Q} 61 \mathrm{H}$ & S & $\mathrm{N}$ \\
\hline & 5 & Liver 19 & $\begin{array}{l}\mathrm{P}^{\text {a }}: K R A S \text { G12D } \\
\mathrm{P}^{\mathrm{b}}: K R A S \text { G12D }\end{array}$ & $K R A S \mathrm{G} 12 \mathrm{D}$ & M & A \\
\hline & 6 & Liver 21 & $P I K 3 C A$ E542K & $P I K 3 C A$ E542K & M & A \\
\hline & 7 & Liver 22 & KRAS G12V & $K R A S \mathrm{G} 12 \mathrm{~V}$ & M & A \\
\hline & 8 & Liver 25 & $K R A S$ G12D & $K R A S$ G12D & M & $\mathrm{N}$ \\
\hline & 9 & Liver 27 & $\begin{array}{l}\text { KRAS G13D } \\
P I K 3 C A \text { Q546K }\end{array}$ & $\begin{array}{l}\text { KRAS G13D } \\
P I K 3 C A \text { Q546K }\end{array}$ & M & A \\
\hline \multirow[t]{6}{*}{$\begin{array}{l}\text { Mutation inconsistent cases beside } \\
K R A S, N R A S \text { or } B R A F(n=6)\end{array}$} & 10 & Liver 01 & $\begin{array}{l}K R A S \text { G12D } \\
P I K 3 C A \text { E545K }\end{array}$ & $K R A S \mathrm{G} 12 \mathrm{D}$ & M & $\mathrm{N}$ \\
\hline & 11 & Liver 14 & $\begin{array}{l}\text { KRAS G12D } \\
\text { PIK3CA H1047R } \\
\text { PIK3CA E545K }\end{array}$ & $\begin{array}{l}\text { KRAS G12D } \\
P I K 3 C A \mathrm{H} 1047 \mathrm{R}\end{array}$ & $\mathrm{S}$ & $\mathrm{N}$ \\
\hline & 12 & Liver 23 & $K R A S \mathrm{G13D}$ & $\begin{array}{l}\text { KRAS G13D } \\
P I K 3 C A \text { H1047R }\end{array}$ & M & $\mathrm{N}$ \\
\hline & 13 & Liver 04 & Wild type & $\begin{array}{l}\mathrm{M} 1^{\mathrm{c}} K I T \text { P573L } \\
\mathrm{M} 2^{\mathrm{d}} \text { wild type }\end{array}$ & $\mathrm{S}$ & A \\
\hline & 14 & Liver 16 & Wild type & EGFR G796S & $\mathrm{S}$ & $\mathrm{N}$ \\
\hline & 15 & Liver 18 & $P I K 3 C A$ E545K & Wild type & $S$ & A \\
\hline \multirow[t]{5}{*}{$\begin{array}{l}\text { Mutation inconsistent cases in } \\
K R A S, N R A S \text { or } B R A F(n=5)\end{array}$} & 16 & Liver 34 & $\begin{array}{l}\text { KRAS G12D } \\
P I K 3 C A \text { E545K }\end{array}$ & PIK3CA E545K & $\mathrm{S}$ & $\mathrm{N}$ \\
\hline & 17 & Liver 07 & $K R A S \mathrm{G} 12 \mathrm{~V}$ & Wild type & S & $\mathrm{N}$ \\
\hline & 18 & Liver 09 & $K R A S \mathrm{G} 12 \mathrm{~V}$ & Wild type & $S$ & $\mathrm{~N}$ \\
\hline & 19 & Liver 13 & $E G F R$ G735C & $K R A S$ G12D & S & $\mathrm{N}$ \\
\hline & 20 & Liver 28 & $\begin{array}{l}\mathrm{P} 1^{\mathrm{a}} N R A S \text { A91V } \\
\mathrm{P} 2^{\mathrm{b}} N R A S \text { A91V } \\
N R A S \mathrm{Q} 61 \mathrm{R}\end{array}$ & $N R A S$ A91V & $\mathrm{S}$ & $\mathrm{N}$ \\
\hline
\end{tabular}

${ }^{\mathrm{a}} \mathrm{P} 1$ : primary site 1

${ }^{\mathrm{b}} \mathrm{P} 2$ : primary site 2

${ }^{\mathrm{c}} \mathrm{M} 1$ : liver metastatic site 1

${ }^{\mathrm{d}} \mathrm{M} 2$ : liver metastatic site 2

or metastasis) in all patients with metastatic colorectal cancer for $R A S$ and $B R A F$. However, most of these reports perform the mutation test using Sanger sequencing or ARMSPCR, which may be limited by low sensitivity or detection of common mutations (Artale et al. 2008; Knijn et al. 2011; Santini et al. 2008). Compared with these traditional technologies, NGS can provide higher sensitivity and border detection ranges. Therefore, using NGS may better uncover the genetic heterogeneity between primary and metastatic tumours.

In this study, we detected the mutation profile between paired primary and liver or lung metastatic tumours using multiple sequencing methods. In general, NGS detected more mutations than qPCR did. We found that the mutation profile discordant rate was high between primary and metastatic CRC, which may influence the treatment decision on anti-EGFR target therapy. There were 11 cases $(11 / 22$, $50 \%$ ) which showed different mutational genes between the primary and the lung metastatic tumours. The gene mutation profiles were different in $R A S$ or $B R A F$ in six of these cases. In four cases, tumours were wild type in primary sites, but were $R A S$ mutant type in lung metastatic sites; in another 1 case, gene mutation changed from KRAS G12D and PIK3CA E545A in primary site to wild type in lung metastatic site. 
Table 6 Gene mutational status among the multiple primary or metastatic site(s) in one case

\begin{tabular}{|c|c|c|c|c|}
\hline Case no. & Location & Gene mutational status & $\begin{array}{l}\text { Synchronous(S)/ } \\
\text { metachronous }(\mathrm{M}) \text { metastasis }\end{array}$ & $\begin{array}{l}\text { Gene mutation consistency } \\
\text { among each site (Yes; Y or } \\
\text { No: N) }\end{array}$ \\
\hline \multirow[t]{3}{*}{ Liver $^{\mathrm{a}} 04$} & $\mathrm{P}^{\mathrm{b}}$ & Wild type & $\mathrm{S}$ & $\mathrm{N}$ \\
\hline & $\mathrm{M}^{\mathrm{c}} 1^{\mathrm{d}}$ & KIT P573L & & \\
\hline & M2 & Wild type & & \\
\hline \multirow[t]{3}{*}{ Liver 28} & $\mathrm{P} 1$ & NRAS A91V & $\mathrm{S}$ & $\mathrm{N}$ \\
\hline & $\mathrm{P} 2$ & NRAS A91V,NRAS Q61R & & \\
\hline & M & NRAS A91V & & \\
\hline \multirow[t]{3}{*}{ Lung $^{\mathrm{e}} 20$} & $\mathrm{P}$ & $B R A F \mathrm{~V} 600 \mathrm{E}$ & M & $\mathrm{Y}$ \\
\hline & M1 & $B R A F$ V600E, PIK3CA E542K & & \\
\hline & M2 & $B R A F \mathrm{~V} 600 \mathrm{E}, P I K 3 C A \mathrm{E} 542 \mathrm{~K}$ & & \\
\hline \multirow[t]{2}{*}{ Liver 12} & $\mathrm{P}$ & $K R A S \mathrm{Q} 61 \mathrm{H}$ & $\mathrm{S}$ & $\mathrm{Y}$ \\
\hline & M1, M2 & KRAS Q61H & & \\
\hline \multirow[t]{2}{*}{ Liver 19} & M & KRAS G12D & M & $\mathrm{Y}$ \\
\hline & $\mathrm{P} 1, \mathrm{P} 2$ & KRAS G12D & & \\
\hline \multirow[t]{2}{*}{ Liver 15} & M1-M3 & Wild type & M & $\mathrm{Y}$ \\
\hline & $\mathrm{P}$ & Wild type & & \\
\hline \multirow[t]{2}{*}{ Liver 17} & M1-M8 & Wild type & M & $\mathrm{Y}$ \\
\hline & $\mathrm{P}$ & Wild type & & \\
\hline \multirow[t]{2}{*}{ Liver 31} & M1-M3 & Wild type & $\mathrm{S}$ & $\mathrm{Y}$ \\
\hline & $\mathrm{P}$ & Wild type & & \\
\hline \multirow[t]{2}{*}{ Liver 33} & M1, M2 & Wild type & $\mathrm{S}$ & $\mathrm{Y}$ \\
\hline & $\mathrm{P}$ & Wild type & & \\
\hline
\end{tabular}

${ }^{\mathrm{a}} \mathrm{CRC}$ with liver metastasis

${ }^{\mathrm{b}}$ Primary site

${ }^{\mathrm{c}}$ Metastatic site

${ }^{\mathrm{d}}$ Numbers of each primary or metastatic site(s)

${ }^{\mathrm{e}} \mathrm{CRC}$ with lung metastasis

There were also 11 cases $(11 / 20,55 \%)$ which showed different mutational genes between the paired primary and liver metastatic CRCs. The gene mutation profiles were different in $R A S$ or $B R A F$ in five of these cases. Three cases were $R A S$ mutant type in primary sites, but were $R A S$ wild type in metastatic sites; on the contrary, another 1 case was $R A S$ wild type in primary site, but was $R A S$ mutant type in metastatic site. We also found that mutation inconsistent cases were much more in CRC with synchronous liver metastasis. These data strongly support the notion that testing the mutational status of metastatic tumours is necessary rather than only testing the mutational status of primary tumours to further guide targeted therapy selection, both in synchronous and metachronous metastatic cases.

Neoadjuvant or adjuvant radiochemotherapy may have potential effect on gene mutation status. Some studies tried to determine if there are any changes in KRAS mutation status before and after preoperative chemoradiotherapy (CRT) in primary CRC. The results were controversial. In the study by Boissiere-Michot et al., KRAS mutation was identified in
9/31 (29\%) surgical specimens which major tumour regression is achieved in locally advanced rectal adenocarcinomas after radiochemotherapy, less than in the paired pretreatment biopsies (12/31, 39\%) (Boissiere-Michot et al. 2012). Jo et al. did not obtain evidence that CRT results in changes of the KRAS mutation pattern and no intratumoural heterogeneity in the KRAS mutational status could be proven before and after neoadjuvant CRT. The discrepancy observed in these studies may be caused by the amount of viable tumour cells after CRT and the sensitivity of the analytical method (Jo et al. 2016). The gene mutation discrepancy between primary and metastatic tumour with or without adjuvant therapy is unknown. In the present study, there were 17 cases which underwent adjuvant chemotherapy in liver metastatic CRC group. We observed that the mutation inconsistent cases were more in non-adjuvant therapy group than in adjuvant therapy group $(9 / 19$ vs $2 / 17, P=0.021)$. This data may show potential therapy-related changes, but it needs to be proven by further larger and well-designed studies. 
The presence of tumour heterogeneity has been found in many cancers and is a possible explanation for therapy resistance (Xie et al. 2014). Several studies have demonstrated the genetic, epigenetic, and transcriptomic heterogeneity in CRC (Jones et al. 2017; Punt et al. 2017). In our study, we tested the mutational status between 65 paired primary and metastatic tumours, including 36 paired primary-liver metastatic tumours and 29 paired primary-lung metastatic tumours. We found that the discordant rate of mutational status between the paired primary and the metastatic tumours was as high as $55 \%$. In addition, more gene mutations were detected in the lung metastatic tumours than those in the primary tumours. The possible explanation is that most lung metastatic tumours are metachronous metastasis. Discordant mutations may be acquired in the lung metastases because of clonal evolution following chemotherapy compared with that in the primary tumours (Findlay et al. 2016).

In addition to predicting the response to EGFR-targeted therapy, the KRAS, NRAS, BRAF, and PIK3CA mutations may also act as significant prognostic factors in CRC (Foltran et al. 2015; Vogelaar et al. 2015). Here, we found that the frequency of $K R A S$ and $B R A F$ mutations was higher in the lung metastatic tumours than that in the liver metastatic tumours. These data indicate that determining the mutation profiling of CRC may have a potential implication for CRC development and progression.

Moreover, some rare gene mutations were observed in our studies, such as the KIT and EGFR mutations. These rare mutations may also act as a potential target for the treatment of CRC, and application of NGS can comprehensively determine the mutational status of CRC (Chen et al. 2015; Cho et al. 2014). However, more studies are necessary to further explore the relationship between these rare mutations and target therapies.

This study has some limitations. First, it is a retrospective study of a single centre. Second, some samples were excluded for poor DNA quality and the number of samples was relatively small. Third, only the resection samples were in the study, which may show case selection bias, because those were all resectable or potentially resectable mCRC, which were in a relatively early stage.

In conclusion, our study demonstrates that the discordance of the gene mutational status between paired primary and metastatic CRC is rather high when detected by NGS. Therefore, evaluating the mutational status of both the primary and the metastatic tumours should be considered in clinical mutation testing to better guide targeted therapies of mCRC.

Authors' contributions SMZ designed and conducted the study, and wrote and submit the manuscript. WHL wrote some of the original manuscript. WMW performed the statistical analyses and wrote some of the original manuscript. WBL analyzed and interpreted of the experimental data. SSS collected, interpreted, and analyzed the clinical data.
JMY designed and managed the study, and evaluated the H\&E slides. NL designed and managed the study, and had final responsibility for the decision to submit for publication.

Funding This study was funded by: 1 . National Key R\&D Program of China (Grant No: 2016YFC0905300). 2. CAMS Innovation Fund for Medical Sciences (CIFMS) (Grant no.2017-I2M-1-006 and 2016I2M-1-001). 3. Beijing Hope Run Special Fund of Cancer Foundation of China (Grant no. LC2014A08 and LC2017A07).

\section{Compliance with ethical standards}

Conflict of interest All authors declare no conflict of interest.

Ethical approval All procedures performed in studies involving human participants were in accordance with the ethical standards of the Cancer Hospital, Chinese Academy of Medical Sciences, National GCP Center for Anticancer Drugs, and The Independent Ethics Committee and with the 1964 Helsinki declaration and its later amendments or comparable ethical standards.

Open Access This article is distributed under the terms of the Creative Commons Attribution 4.0 International License (http://creativeco mmons.org/licenses/by/4.0/), which permits unrestricted use, distribution, and reproduction in any medium, provided you give appropriate credit to the original author(s) and the source, provide a link to the Creative Commons license, and indicate if changes were made.

\section{References}

Artale S et al (2008) Mutations of KRAS and BRAF in primary and matched metastatic sites of colorectal cancer. J Clin Oncol 26:4217-4219. https://doi.org/10.1200/jco.2008.18.7286

Boissiere-Michot F et al (2012) KRAS genotyping in rectal adenocarcinoma specimens with low tumour cellularity after neoadjuvant treatment. Mod Pathol 25:731-739. https://doi.org/10.1038/ modpathol.2011.210

Chen EC et al (2015) KIT signaling promotes growth of colon xenograft tumours in mice and is up-regulated in a subset of human colon cancers. Gastroenterology 149:705-717.e702. https://doi. org/10.1053/j.gastro.2015.05.042

Chen W et al (2016) Cancer statistics in China. 2015 CA Cancer J Clin 66:115-132. https://doi.org/10.3322/caac.21338

Cho J et al (2014) Colon cancer-derived oncogenic EGFR G724S mutant identified by whole genome sequence analysis is dependent on asymmetric dimerization and sensitive to cetuximab. Mol Cancer 13:141. https://doi.org/10.1186/1476-4598-13-141

Dietel M et al (2015) A 2015 update on predictive molecular pathology and its role in targeted cancer therapy: a review focussing on clinical relevance. Cancer Gene Ther 22:417-430. https://doi. org/10.1038/cgt.2015.39

Efferth T (2012) Signal transduction pathways of the epidermal growth factor receptor in colorectal cancer and their inhibition by small molecules. Curr Med Chem 19:5735-5744

Findlay JM et al (2016) Differential clonal evolution in oesophageal cancers in response to neo-adjuvant chemotherapy. Nat Commun 7:11111. https://doi.org/10.1038/ncomms11111

Foltran L et al (2015) Prognostic role of KRAS, NRAS, BRAF and PIK3CA mutations in advanced colorectal cancer. Future Oncol 11:629-640. https://doi.org/10.2217/fon.14.279 
Goswami RS et al (2015) Hotspot mutation panel testing reveals clonal evolution in a study of 265 paired primary and metastatic tumours. Clin Cancer Res 21:2644-2651. https://doi.org/10.1158/10780432.ccr-14-2391

Haley L et al (2015) Performance characteristics of next-generation sequencing in clinical mutation detection of colorectal cancers. Mod Pathol 28:1390-1399. https://doi.org/10.1038/modpa thol.2015.86

Han CB, Li F, Ma JT, Zou HW (2012) Concordant KRAS mutations in primary and metastatic colorectal cancer tissue specimens: a meta-analysis and systematic review. Cancer Invest 30:741-747. https://doi.org/10.3109/07357907.2012.732159

Hsu HC et al (2016) Mutations of KRAS/NRAS/BRAF predict cetuximab resistance in metastatic colorectal cancer patients. Oncotarget 7:22257-22270. https://doi.org/10.18632/oncotarget.8076

Jo P et al (2016) Heterogeneity of KRAS mutation status in rectal cancer. PLoS One 11:e0153278. https://doi.org/10.1371/journ al.pone. 0153278

Jones HG, Jenkins G, Williams N, Griffiths P, Chambers P, Beynon J, Harris D (2017) Genetic and epigenetic intra-tumour heterogeneity in colorectal cancer. World J Surg 41:1375-1383. https://doi. org/10.1007/s00268-016-3860-z

Karthaus M et al (2016) Impact of tumour RAS/BRAF status in a first-line study of panitumumab + FOLFIRI in patients with metastatic colorectal cancer. Br J Cancer 115:1215-1222. https://doi. org/10.1038/bjc.2016.343

Knijn N et al (2011) KRAS mutation analysis: a comparison between primary tumours and matched liver metastases in 305 colorectal cancer patients. Br J Cancer 104:1020-1026. https://doi. org/10.1038/bjc.2011.26

Kothari N, Schell MJ, Teer JK, Yeatman T, Shibata D, Kim R (2014) Comparison of KRAS mutation analysis of colorectal cancer samples by standard testing and next-generation sequencing. J Clin Pathol 67:764-767. https://doi.org/10.1136/jclinpath-2014202405

Li ZZ et al (2016) Mutation profiling in chinese patients with metastatic colorectal cancer and its correlation with clinicopathological features and anti-EGFR treatment response. Oncotarget 7:2835628368. https://doi.org/10.18632/oncotarget.8541

Malapelle U et al (2015) Ion Torrent next-generation sequencing for routine identification of clinically relevant mutations in colorectal cancer patients. J Clin Pathol 68:64-68. https://doi.org/10.1136/ jclinpath-2014-202691

Nakayama I et al (2017) Retrospective study of RAS/PIK3CA/BRAF tumour mutations as predictors of response to first-line chemotherapy with bevacizumab in metastatic colorectal cancer patients. BMC Cancer 17:38. https://doi.org/10.1186/s12885-016-2994-6

Punt CJ, Koopman M, Vermeulen L (2017) From tumour heterogeneity to advances in precision treatment of colorectal cancer. Nat Rev Clin Oncol 14:235-246. https://doi.org/10.1038/nrcli nonc.2016.171

Santini D et al (2008) High concordance of KRAS status between primary colorectal tumours and related metastatic sites: implications for. clinical practice Oncologist 13:1270-1275. https://doi. org/10.1634/theoncologist.2008-0181

Sinicrope FA, Okamoto K, Kasi PM, Kawakami H (2016) Molecular biomarkers in the personalized treatment of colorectal cancer. Clin Gastroenterol Hepatol 14:651-658. https://doi.org/10.1016/j. cgh.2016.02.008

Van Cutsem E et al (2016) ESMO consensus guidelines for the management of patients with metastatic colorectal cancer. Ann Oncol 27:1386-1422. https://doi.org/10.1093/annonc/mdw235

Vogelaar F, Van Erning F, Reimers M, Van Der Linden J, Pruijt J, Van Den Brule A, Bosscha K (2015) The prognostic value of microsatellite instability, KRAS, BRAF and PIK3CA mutations in stage II colon cancer patients. Mol Med. https://doi.org/10.2119/molme d.2015.00220

Xie T et al (2014) Patterns of somatic alterations between matched primary and metastatic colorectal tumours characterized by wholegenome. Seq Genom 104:234-241. https://doi.org/10.1016/j. ygeno.2014.07.012 